\title{
Mixed Plastic Wastes Pyrolysis in a Fluidized Bed Reactor for Potential Diesel Production
}

\author{
Aida Isma M. I., Salmiaton A., and Nur Dinie K. B.
}

\begin{abstract}
Disposing of waste to landfill has becoming undesirable to the legislation pressures, rising costs and the poor biodegradable quality of polymer used. Feasible study on converting mixed plastic wastes by applying catalytic pyrolysis into valuable products had been carried out. Thermogravimetric analysis under various heating rates and particle sizes were determined. A $15 \mathrm{~g} / \mathrm{h}$ of fluidized bed lab scale of fast pyrolysis unit was used. The pyrolysis processes were carried out at temperature of $400^{\circ} \mathrm{C}$ for 2 hours in non-catalytic and catalytic conditions with ratio catalyst to mixed plastic waste of 10:90. The properties of liquid products were analysed and compared using Fourier Transform Infrared Spectroscopy (FTIR) and High-Pressure Liquid Chromatography (HPLC). Under the experimental conditions, the maximum liquid yields with and without catalyst were 20 and $35 \mathrm{ml}$, respectively. FTIR results revealed that those functional groups detected are similar with commercial diesel together with HPLC results indicating diesel concentration.
\end{abstract}

Index Terms-Mixed plastic wastes, pyrolysis, catalytic, diesel.

\section{INTRODUCTION}

The problem of solid waste disposal is growing throughout the world, as a result of industrialization and population growth. The huge population increase couple with the improved living conditions of people lead to a dramatically increase of the consumption of plastics worldwide. The major usages of plastic are packaging, households and domestic products, electrical and electronic goods as well as building, construction and automotive industries. It was estimated that 170 million tons of plastics were produced worldwide during the year 2003 [1]. Based on statistics for the Western Europe, the annual 2003 total consumption of plastic products was estimated at 48.8 million tons corresponding to $98 \mathrm{~kg} /$ capita [2]. In the United States, the total amount of plastic in municipal solid waste (MSW) was approximately 30 million tons, which was represented as $11.7 \%$ of total MSW in 2006 [3]. Recycling plastic wastes by chemical reactions such as pyrolysis has made it possible to recover enormous energy recovery [4].

Pyrolysis could be an alternative to landfill or incineration for these rejected streams. In the pyrolysis process (heating in

Manuscript received July 18, 2014, revised October 18, 2014. This work was financially supported by the Kementerian Pengajian Tinggi (KPT) Malaysia (FGRS/1/2012) under Grant Fundamental Research Grant Scheme (FRGS).

Aida Isma M. I. is with SEGi University, Petaling Jaya, 47810 Selangor DarulEhsan, Malaysia (e-mail: aidaisma@segi.edu.my).

Salmiaton Ali is with the Department of Chemical and Environmental Engineering, Faculty of Engineering, Universiti Putra Malaysia, Serdang 43400 Selangor DarulEhsan, Malaysia (e-mail: mie@upm.edu.my).

Nur Dinie was with Universiti Putra Malaysia, Serdang 43400 Selangor DarulEhsan, Malaysia. an oxygen free atmosphere), the organic components of the materials are decomposed generating liquid and gaseous products, which can be useful as fuels and/or feedstock of chemicals for other chemical processing [5]. The yield and the composition of the products influence by a range of pyrolysis process parameters, including the type of waste, reactor system, gas residence time, contact time, heating rate, temperature, pressure ranges, presence of catalyst and presence of hydrogen gas or hydrogen donor compound [6]-[9].

Temperature has been the most influenced factor and has been one of the common studied operating parameter affecting the process of thermal cracking of the plastics, and as a consequence has a strong effect on the pyrolysis products and on the secondary reactions [10]-[12]. Several authors have studied the influence of operating parameters [13]-[18] and type of equipment [19]-[24] on pyrolysis of one or a selected amount of components of the MSW. The influence of catalyst on the yield and composition of products has been extensively investigated [25]. Many of the research have been carried out on a single plastic or in simple plastic mixtures, whilst there are few data on plastics collected from real municipal plastic wastes.

The dominant components of waste plastics such as polypropylene (PP), polystyrene (PS) and polyethylene (PE) are rich in carbon and hydrogen, which are the building blocks of petroleum. Therefore, the possibility of converting mixed plastic waste into liquid fuels is a productive alternative for plastic recycling. The aim of this work was to investigate the thermal degradation of plastic waste in a fluidized bed with and without catalyst for potential diesel production. The effects of heating rate and the particle size were also evaluated.

\section{EXPERIMENT}

\section{A. Raw Material}

The plastic mixture used in this study was a simulated fraction of that found in MSW of Kuala Lumpur, Malaysia. Mixed plastic wastes that consist of PE, PP and PS with ratio of 5:3:1 were cut into smaller sizes $(5 \mathrm{~mm} \times 5 \mathrm{~mm})$ and mixed. The proximate value was characterized using Thermogravimetric Analyzer (Mettler Toledo, TGA/SDTA 851, USA). Experiment was repeated by adding a fluidized catalytic cracking (FCC) catalyst for process enhancement and product selectivity. The ratio of catalyst to mixed plastics was 10:90.

\section{B. Solvents and Others}

Locally available $99.9 \%$ pure $\mathrm{N}_{2}$ gas and HPLC grade hexane, toluene and dichloromethane (DCM) solvents from 
Fisher Scientific were used in the reactions.

\section{Proximate Analysis}

Ten milligrams of the sample at particle size of 1, 2, 2.5 and $4 \mathrm{~mm}$ were heated from room temperature to $600^{\circ} \mathrm{C}$ with different heating rate of $5,10,20$ and $30^{\circ} \mathrm{C} / \mathrm{min}$ under nitrogen $\left(\mathrm{N}_{2}\right)$ with a constant flow rate of $20 \mathrm{~mL} \mathrm{~min}^{-1}$. Fig. 2(a) and 2(b) shows the thermogravimetric (TG) and derivative thermogravimetric (DTG) curves of mixed plastic wastes.

\section{FTIR Analysis}

The FTIR spectra were recorded by applying an attenuated total reflectance (ATR) crystal. The instrument used was a spectrophotometer of Perkin Elmer, Spectrum One. The resolution of the equipment was $4 \mathrm{~cm}^{-1}$. The FTIR spectrum in the significant ranges of 4000 to $650 \mathrm{~cm}^{-1}$ was measured and recorded. A commercial software spectrum v.5.0.1 (Perkin - Elmer LLC 1500F2429) was used to process and calculate all data from the spectra. The elemental compositions value of bio-oil was determined.

\section{E. HPLC Analysis}

HPLC analyses were carried out using $n$-hexane as the solvent. The column used was the amino propyl silica-dual column $(25 \mathrm{~cm} \times 4.6 \mathrm{~mm})$. The instrument used was the Waters 515 with UV and RI detectors. The 16 priority polyaromatic hydrocarbons (PAHs) in the pyrolysis products and in a commercial diesel were analyzed with High Performance Liquid Chromatography (HPLC) equipped with wavelength scanning ultraviolet (UV) detector.

\section{F. Pyrolysis}

All experiments took place in the Combustion Laboratory of Chemical and Environmental Engineering Department, Universiti Putra Malaysia, Serdang, Selangor DarulEhsan, Malaysia. The pyrolysis experiments were performed using an unstirred fluidized-bed bench scale reactor made of stainless steel with a diameter of $52 \mathrm{~mm}$ and a height of 36.5 $\mathrm{cm}$. A schematic diagram of the reactor is shown in Fig. 1. Two different pyrolysis experiments were performed: (1) Non-catalytic plastic pyrolysis, and (2) Catalytic plastic pyrolysis.

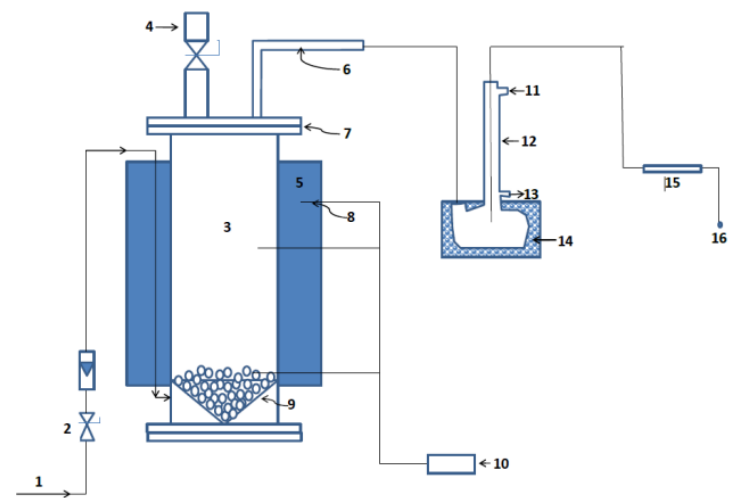

Fig. 1. Schematic diagram of experimental setup. (1) N2 gas inlet, (2) flow meter, (3) lab scale reactor, (4) feeder, (5) electric furnace, (6) gas discharge, (7) flange, (8) thermocouple, (9) distributor, (10) temperature control panel, (11) cooling water supply, (12) condenser, (13) cooling water outlet, (14) ice bath, (15) silica gel, (16) flue gas outlet.

Approximately $30 \pm 5 \mathrm{~g}$ of dried plastic samples were pre-blended together with $100 \mathrm{~g}$ of inert sand and was placed in the reactor and after all the connections were made, sweeping gas flow rate of $9 \mathrm{~L} / \mathrm{min}$ was adjusted and measured by a flow meter. The heating rate of $10^{\circ} \mathrm{C} \min ^{-1}$ was kept constant in all experiments. The sample was pyrolysed to the final pyrolysis temperature of $400^{\circ} \mathrm{C}$ for 2 hours. The pyrolysis experiment was repeated using FCC catalyst. The pyrolysis was performed to determine the influence of temperature and time on the yield of pyrolysis products.
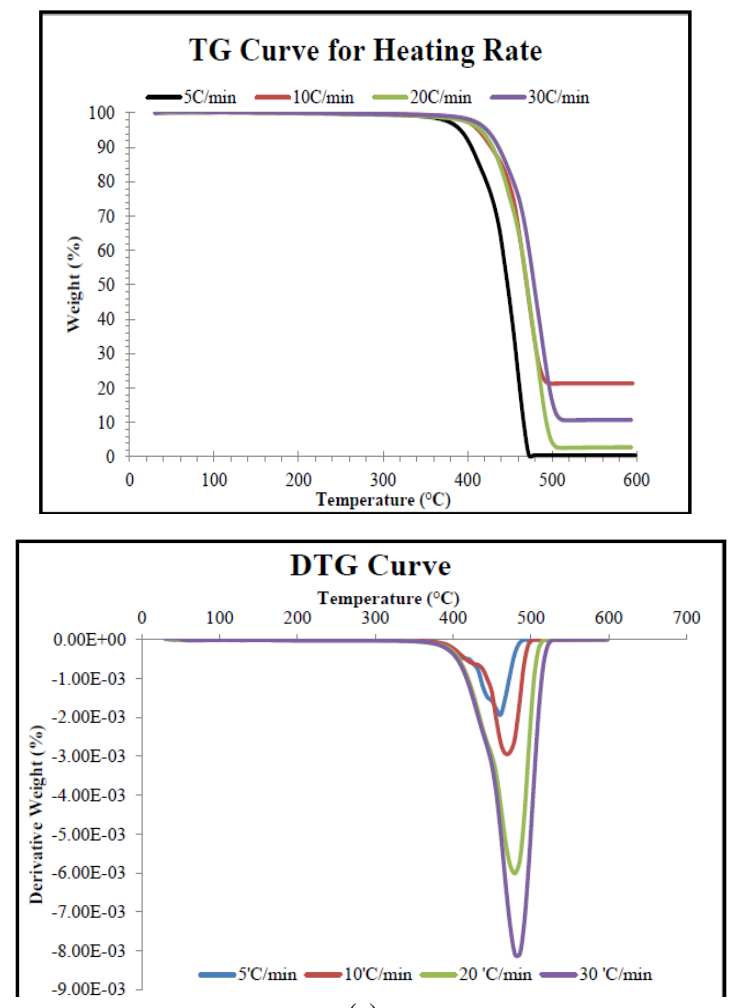

(a)
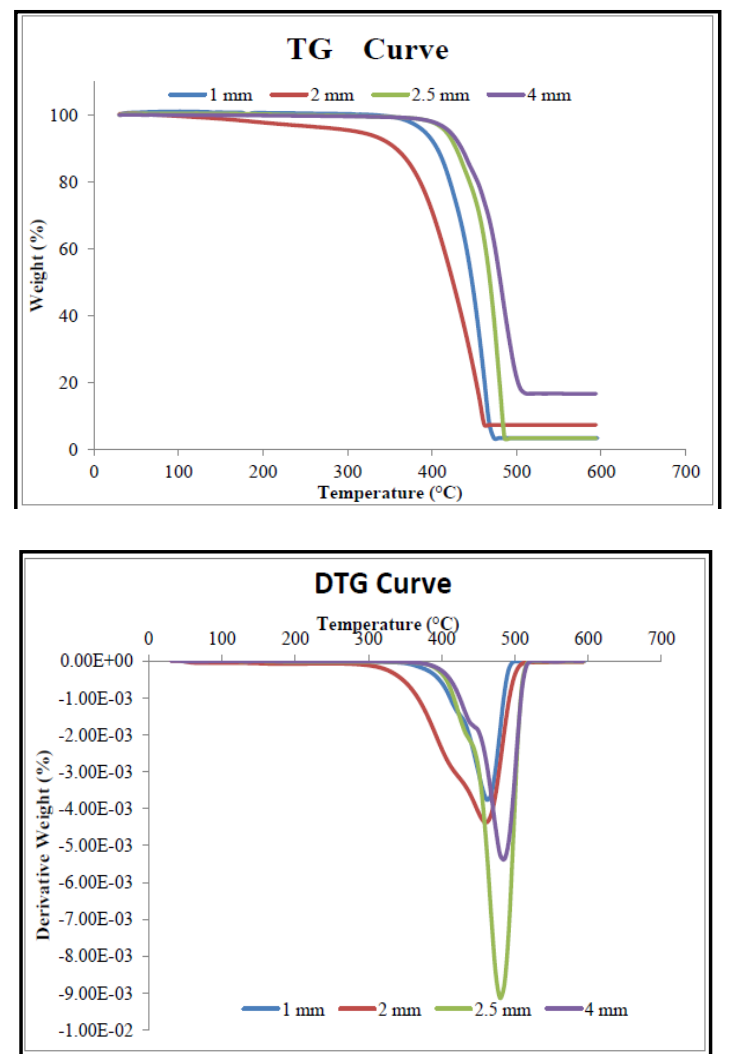

(b)

Fig. 2. TG and DTG plots of mixed plastics waste: (a) at different heating time, (b) at different particle size. 
The pyrolysis liquid products were collected by condensing in condenser and cold traps maintained at about $0^{\circ} \mathrm{C}$ to $5^{\circ} \mathrm{C}$ and were washed by DCM. The liquid obtained from the maximum pyrolysis yield were characterized using FTIR and HPLC.

\section{RESULTS}

\section{A. Pyrolysis Yields}

Chemical properties and distribution of separated hydrocarbon compounds were strongly dependent on the reaction conditions and material fed into the reactor [26], [27]. The liquid yields obtained with the two mentioned pyrolysis method, are presented in Table I. It can be stated that the catalyst plays an important role in pyrolysis product distribution, producing more liquids.

TABLE I: PRODUCT YIELdS FROM THE PYROLYSIS OF MIXED PlastiC

\begin{tabular}{|l|c|}
\hline Wethods & Liquid (DCM + diesel)mL \\
\hline Non-catalytic condition & 20 \\
\hline Catalytic condition & 35 \\
\hline
\end{tabular}

\section{B. Heating Rate and Particle Size Effects}

For a better understanding of the thermal behavior of the samples, the TGA plots are presented as shown in Fig. 2. Fig. 2a shows the weight loss of samples as a function of heating rate of $5,10,20$ and $30^{\circ} \mathrm{C} / \mathrm{min}$ and Fig. 2(b) shows the degradation at different particle sizes of $1,2,2.5$ and $4 \mathrm{~mm}$. As portrayed in the figures, all plastics loss its weight at temperature of approximately $400^{\circ} \mathrm{C}$. As the heating rates increase, the peaks are shifted towards the high range of temperature. The analysis of differential thermo-gravimetric (DTG) curves also shows that best particle size of $2.5 \mathrm{~mm}$ decomposed at $400^{\circ} \mathrm{C}$.

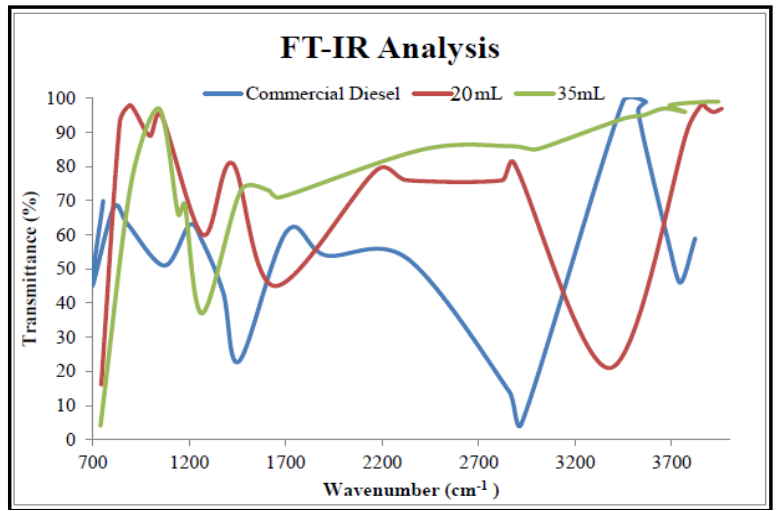

Fig. 3. FTIR results for commercial diesel, liquid containing dichloromethane (DCM) and diesel.

\section{FTIR Analysis}

The contents of $\mathrm{C}$ and $\mathrm{H}$ are important indicators for the quality of the liquid products. The chemical structure of the pyrolysis yields and the commercial diesel was confirmed by recording their IR spectra. Fig. 3 shows the FTIR spectra of the commercial diesel, the experimental yields at 20 and $35 \mathrm{ml}$, respectively. As observed, liquid containing DCM and diesel at 20 and $35 \mathrm{ml}$ show almost the same curves as the commercial diesel. The spectra shows that various functional groups occurring in abundance and represented by broad absorption bands in a regions of hydroxyl groups(3570-3200 $\left.\mathrm{cm}^{-1}\right)$, methylene stretch $\left(2865-2845 \mathrm{~cm}^{-1}\right)$ and aromatic C-H in plane bend $\left(1225-920 \mathrm{~cm}^{-1}\right)$.

\section{HPLC Analysis}

The concentration of diesel increased sharply with presence of FCC catalyst temperature of $400^{\circ} \mathrm{C}$. This is because catalyzed reactions have lower activation energy resulting a higher reaction rate at the same temperature as shown in Table II.

TABLE II: DIESEL YIELD (CONCENTRATIONS) FOR ALL CONDITIONS AND METHOD

\begin{tabular}{|l|c|c|c|}
\hline $\begin{array}{l}\text { Conditions / Method } \\
\text { at temp. } 400^{\circ} \mathrm{C}\end{array}$ & $\begin{array}{c}\text { Area at the } \\
\text { retention time }\end{array}$ & $\begin{array}{c}\text { Diesel yield } \\
(\mathrm{mg} / \mathrm{L})\end{array}$ & $\begin{array}{c}\text { Liquid } \\
(\mathrm{DCM}+ \\
\text { Diesel), mL }\end{array}$ \\
\hline Normal condenser: & & & \\
\hline Non-catalytic & 9,732 & $1,734.62$ & 20 \\
\hline Catalytic & 58,113 & $10,358.00$ & 15 \\
\hline $\begin{array}{l}\text { Improved } \\
\text { condenser: }\end{array}$ & & & \\
\hline Catalytic & 151,379 & $26,981.64$ & 35 \\
\hline
\end{tabular}

The determination of aliphatics (mainly saturates) and aromatic groups (mono, di and poly-aromatics) in the liquid products obtained from the pyrolysis of mixed plastic wastes are of great importance for their utilization. Fig.4(a) shows the HPLC results of a commercial diesel from Malaysia,Fig. 4(b) HPLC results of non catalyst at $20 \mathrm{~mL}$, Fig. 4(c) HPLC results of catalyst at $15 \mathrm{~mL}$ and Fig. 4(d) HPLC results with the presence of catalyst at $35 \mathrm{~mL}$. It should be noted that the compound found in the experimental yield support the presence of the potential diesel production.

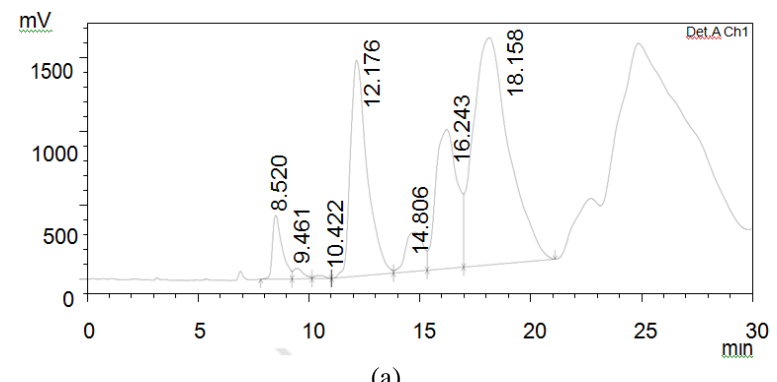

$\mathrm{mV}$

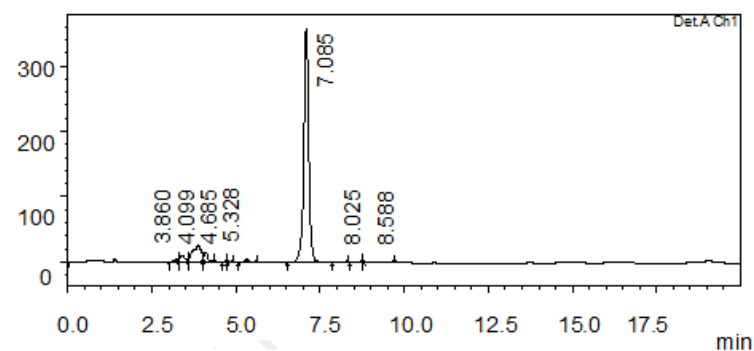

(b)

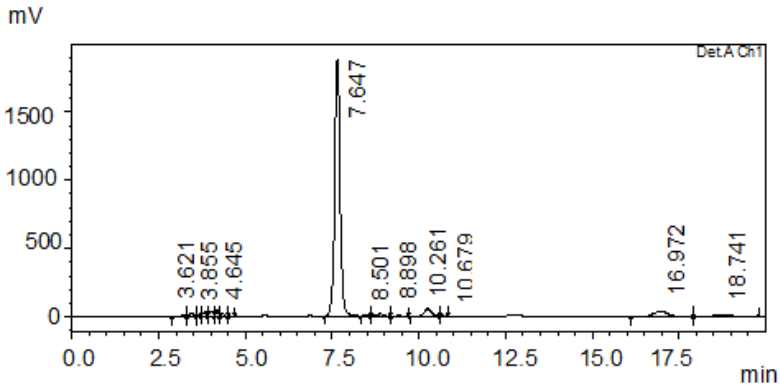

(c) 
$\mathrm{mV}$

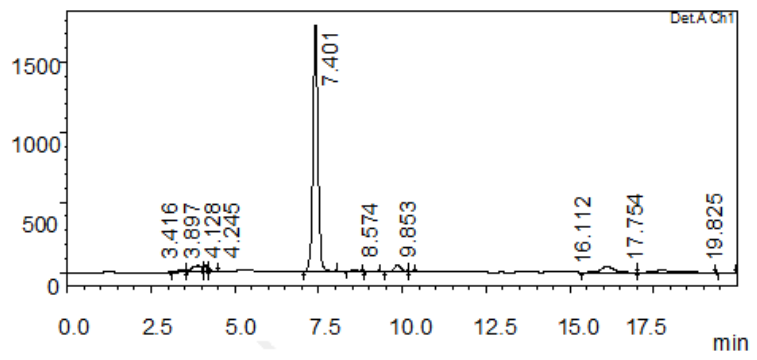

(d)

Fig. 4. HPLC spectra of diesel concentration: (a) commercial diesel, (b) non catalyst $20 \mathrm{ml}, \mathrm{v})$ with catalyst $(15 \mathrm{ml})$, (d) with catalyst $(35 \mathrm{ml})$.

\section{CONCLUSION}

Pyrolysis is an attractive alternative for recycling mixed plastic wastes and the use of catalyst can significantly enhance the process. It can be concluded that FCC catalyst is an effective catalyst which enhances the production of aromatic liquid products. Pyrolysis products may be used as an alternative fuels or as a source of valuable chemicals.

\section{ACKNOWLEDGMENT}

The authors wish to thank the Department of Chemical and Environmental Engineering, Universiti Putra Malaysia for supporting this work. This paper has been made possible by means of research grant provided by the Fundamental Research Grant Scheme (FRGS) of the Kementerian Pengajian Tinggi (KPT), Malaysia.

\section{REFERENCES}

[1] D. S. Achilias, C. Roupakias, P. Megolokonomos, A. A. Lappas, and E. V. Antonakou, "Chemical recycling of plastic wastes from polyethylene (LDPE and HDPE) and polypropylene (PP)," Journal of Hazardous Material, vol. 149, pp. 536-542, 2007.

[2] Plastics Europe (Association of Plastics Manufacturers). [Online]. Available: http://www.plasticseurope.org

[3] United States Environment Protection Agency (USEPA). Municipal Solid Waste Generation, Recycling and Disposal in the United States: Facts and Figures for 2006. [Online]. Available: http://www.epa.gov/garbage/plastic.htm

[4] F. Sasse and G. Emig, "Review: Chemical recycling of polymer materials," Chem. Eng. Tech., vol. 21, no. 10, pp. 777-789, 1998.

[5] A. López, I. de Marco, B. M. Caballero, M. F. Laresgoiti, and A. Adrados, "Influence of time and temperature on pyrolysis of plastics waste in a semi-batch reactor," Chemical Engineering Journal, vol. 173, no. 62, pp. 62-71, 2011.

[6] P. T. Williams and E. J. Slaney, "Analysis of products from the pyrolysis and liquefaction of single plastics and waste plastic mixtures," Resour. Conserv. Recycl., vol. 51, pp. 754-769, 2007.

[7] J. Shah, M. R. Jan, and Z. Hussain, "Catalytic pyrolysis of low-density polyethylene with lead sulfide into fuel oil," Polym. Degrad. Stab., vol. 87, pp. 329-333, 2005.

[8] H. Haykiri-Acma, S. Yaman, and S. Kucukbayrak, "Effect of heating rate on the pyrolysis yields of rapeseed," Renew. Energy, vol. 31, pp. 803-810, 2006

[9] W. Kaminsky and I.-J. N. Zorriqueta, "Catalytical and thermal pyrolysis of polyolefins," J. Anal. Appl. Pyrol., vol. 79, pp. 368-374, 2007.
[10] A. M. Li, S. Q. Li, Y. Ren, Y. Chi, J. H. Yan, and K. F. Cen, "Pyrolysis of solid waste in a rotary kiln: Influence of final pyrolysis temperature on the pyrolysis products," J. Anal. Appl. Pyrolysis, vol. 50, pp. 149-162, 1999.

[11] T. Yoshioka, G. Grause, C. Eger, W. Kaminsky, and A. Okuwaki, "Pyrolysis of poly (ethyleneterephthalate) in a fluidised bed plant," Polym. Degrad. Stab., vol. 86, pp. 499-504, 2004.

[12] L. Ji, A. Hervier, and M. Sablier, "Study on the pyrolysis of polyethylene in the presence of iron and copper chlorides," Chemosphere, vol. 65, pp. 1120-1130, 2006.

[13] C.-H. Wu, C.-Y. Chang, J.-P. Lin, and J.-Y. Hwang, "Thermal treatment of coated printing and writing paper in MSW: pyrolysis kinetics," Fuel, vol. 76, pp. 1151-1157, 1997.

[14] O. Senneca, P. Salatino, and R. Chirone, "Fast heating-rate thermogravimetric study of the pyrolysis of scrap tyres," Fuel, vol. 78, pp. 1575-1581, 1999.

[15] S. Kim, "Pyrolysis kinetics of waste PVC pipe," Waste Manage., vol. 21, pp. 609-616, 2001.

[16] L. Sorum, M. G. Gronli, and J. E. Hustad, "Pyrolysis characteristics and kinetics of municipal solid wastes," Fuel, vol. 80, pp. 1217-1227, 2001.

[17] S. S. Kim and F. A. Agblevor, "Pyrolysis characteristics and kinetics of chicken litter," Waste Manage, vol. 27, pp. 135-140, 2007.

[18] J. Zheng, Y. Q. Jin, Y. Chi, J.-M. Wen, X.-G. Jiang, and M.-J. Ni, "Pyrolysis characteristics of organic components of municipal solid waste at high heating rates," Waste Manage, vol. 29, pp. 1089-1094, 2009.

[19] K. Kawaguchi, K. Miyakoshi, and K. Momonoi, "Studies on the pyrolysis behavior of gasification and melting system for municipal solid waste," J. Mater. Cycles Waste Manage, vol. 4, p. 102, 2002.

[20] V. Sricharoenchaikul, A. L. Hicks, and W. J. Frederick, "Carbon and char residue yields from rapid pyrolysis of kraft black Liquor," Bioresour. Technol., vol. 77, pp. 131-138, 2001.

[21] I. Demiral and S. Sensoz, "The effects of different catalysts on the pyrolysis of industrial wastes (olive and hazelnut bagasse)," Bioresour. Technol., vol. 99, pp. 8002-8007, 2008.

[22] X. J. Guo, B. Xiao, X. L. Zhang, S. Y. Luo, and M. Y. He, "Experimental study on air-stream gasification of biomass micron fuel (bmf) in a cyclone gasifier," Bioresour. Technol., vol. 100, pp. 1003-1009, 2009.

[23] W. Kaminsky and J. S. Kim, "Pyrolysis of mixed plastics into aromatics," J. Anal. Appl. Pyrol., vol. 51, pp. 127, 1999.

[24] A. Mountouris, E. Voutsas, and D. Tassios, "Solid waste plasma gasification: equilibrium model development and exergy analysis," Energy Convers. Manage, vol. 47, pp. 1723-1737, 2006.

[25] P. T. Williams and E. Slaney, "Analysis of products from the pyrolysis and liquefaction of single plastics and waste plastic mixtures," Resources, Conservation and Recycling, vol. 51, pp. 754-769, 2007.

[26] N. Kiran, E. Ekinci, and C. E. Snape, "Recycling plastics wastes via pyrolysis," Resource Conservation and Recycling, vol. 29, pp. 273-285, 2000.

[27] J. K. Koo, S. W. Kim, and Y. H. Seo, "Characterization of aromatic hydrocarbon formation from pyrolysis of polyethylene and polystyrene mixtures," Resources Conservation and Recycling, vol. 5, pp. 365-382, 1991.

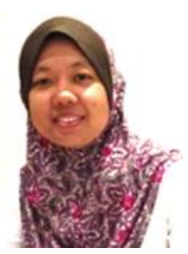

Aida Isma M. I. is a senior lecturer at the Chemical Engineering Department of SEGi University, Kota Damansara since August 2008. Aida has a B.Sc. degree in chemical engineering and M.Sc. degree in environmental engineering from UPM. She is currently pursuing the $\mathrm{Ph} . \mathrm{D}$ degree in environmental engineering in the same university, specializing in membrane technology. Apart from teaching, she is also working on several research projects funded by Ministry of Higher Education Malaysia through Fundamental Research Grants Scheme (FRGS) grants and the internal fund of SEGi University. Her research interest includes membrane technology, waste to energy, water and wastewater treatment. 